\title{
Coordination and Participation in Living Lab Networks Seppo Leminen
}

\author{
"To raise new questions, new possibilities, to regard old" \\ problems from a new angle, requires creative imagination \\ and marks real advance in science.
}

Albert Einstein (1879-1955)

Theoretical physicist and Nobel laureate (1921)

\begin{abstract}
Previous research on living labs has emphasized the importance of users and a real-life environment. However, the existing scholarly discourse lacks understanding of innovation mechanisms in diverse living lab networks, especially from the perspectives of coordination and participation. This study addresses the research gaps by constructing a framework for analyzing coordination (i.e., top-down versus bottom-up) and participation (i.e., inhalation-dominated versus exhalation-dominated) approaches in living lab networks. The classification is based on a literature review and an analysis of 26 living labs in four countries. Given that inhalation and exhalation dominance have not been discussed previously in the innovation literature, the study provides novel ways for both scholars and managers wishing to exploit or explore innovations in living labs. The framework reveals the opportunities for practitioners of innovation with respect to coordination and participation in living lab networks.
\end{abstract}

\section{Introduction}

Familiarity with user requirements and preferences is a prerequisite for companies and organizations. Engaging users as a part of innovation has been shown to increase company performance across various industries (Edvardsson et al., 2010; tinyurl.com/3exkqua). Engaging and involving customers and users as co-developers of innovation strengthen that trend; users participate in many ways to develop brands, experiences, designs, marketing strategies, products, and services (Jeppesen and Molin, 2003: tinyurl.com/k2h604r; Zwick et al., 2008: tinyurl.com/mp9hxk7).

Huizingh (2011; tinyurl.com/kfqyd4l) provides an overview of open innovation and calls for more research on conceptual clarification. Living labs, as an emerging mode of open innovation, have attracted the research community (Almirall and Wareham, 2011; tinyurl.com/lrz3dg2). Almirall, Lee, and Wareham (2012; timreview.ca/article/603) outline the characteristics of living labs in terms of user involvement, operation in real-life contexts, and publicprivate partnerships. Similar to other innovation networks, living labs have been shown to cover various innovation activities and lead to diverse outcomes (Pittaway et al., 2004: tinyurl.com/mdfaap5; Almirall and Wareham, 2011: tinyurl.com/lrz3dg2; Leminen et al., 2012: timreview.ca/article/602). As one form of open innovation network, living labs contain four types of key actors: users, providers, utilizers, and enablers (Westerlund and Leminen, 2011; timreview.ca/article/489).

Living labs stress the importance of users in innovation activities, and their roles are widening from passive informants into co-creators (Leminen, Westerlund, and Nyström, 2014: forthcoming in Volume 9 (Issue 1) of the International Journal of Technology Marketing, tinyurl.com/mdug2zv). The diversity of roles played by users and other stakeholders reflects the spectrum of living lab networks (Nyström, Leminen, Westerlund, and Kortelainen, 2014: forthcoming in Industrial Marketing Management; tinyurl.com/bwmn2vy). Furthermore, 


\section{Coordination and Participation in Living Lab Networks}

Seppo Leminen

Leminen, Westerlund, and Nyström (2012; timreview.ca/ article/602) argue that living lab networks are characterized by the type of actor that is driving the innovation and the mechanisms by which the actors' goals are achieved. Despite the growing interest and attempts to distinguish the various types of living labs, their underlying innovation mechanisms and their link with the party driving the innovation in living lab networks need more research (cf. Følstad, 2008: tinyurl.com/m9wa2dc; Dutilleul et al., 2010; tinyurl.com/k3v3yzo). Therefore, this study aims at understanding innovation mechanisms in living labs. The research questions are as follows:

\section{What are the different coordination and participation approaches in living lab networks?}

\section{How are these approaches linked to diverse living lab networks?}

The article is organized into three main sections. In the first section, it reviews the theoretical foundations of living labs and discusses coordination approaches in term of two opposing forms of coordination: top-down and bottom-up. Next, it describes the research methodology including data collection and analysis. In the third section, the article summarizes findings and reports on two participation approaches (i.e., inhalation-dominated and exhalation-dominated) to innovation based on the analyzed cases. The article concludes by constructing a framework for understanding innovation in living labs, including the dimensions of coordination approach and participation approach.

\section{Living Labs as Open Innovation Networks}

According to Følstad (2008; tinyurl.com/m9wa2dc) and Dutilleul, Birrer, and Mensink (2010; tinyurl.com/k3v3yzo), living labs are grounded on diverse assumptions. These assumptions give rise to open innovation management and the innovation approaches in living labs. Prior research has explored living labs from diverse perspectives including socio-technological systems (Budweg et al., 2011; tinyurl.com/8u3yhvv), ICT innovation development (Følstad, 2008; tinyurl.com/m9wa2dc), operations and functions (Almirall and Wareham, 2011; tinyurl.com/ lrz3dg2), processes (Katzy et al., 2012; tinyurl.com/lvroe2d), social constructions (Dutilleul et al., 2010; tinyurl.com/ k3v3yzo), methodologies (Almirall et al., 2012: timreview.ca/article/603; Schuurman and De Marez, 2012: timreview.ca/article/606; Mulder, 2012: timreview.ca/article/ 607), key principles (Ståhlbröst, 2012; tinyurl.com/l8ur4cu), motivation (Ståhlbröst and Bergvall-Kåreborn, 2011; tinyurl.com/ll2sy7k), user roles (Leminen, Westerlund, and
Nyström, 2014: forthcoming in Volume 9 (Issue 1) of the International Journal of Technology Marketing, tinyurl.com/lqt93mm), and actors' role patterns (Nyström, Leminen, Westerlund, and Kortelainen, 2014: forthcoming in Industrial Marketing Management; tinyurl.com/ kn63gxw).

According to Dutilleul, Birrer, and Mensink (2010; tinyurl.com/k3v3yzo), the term "living lab" has diverse meanings. It can refer to: i) an innovation system; ii) experimentation of a technology; iii) involving users in the product development process; iv) organizations facilitating the network and offering relevant services; or v) the European living lab movement. Living labs are grounded on real-life contexts, user involvement, and publicprivate partnership (Almirall et al., 2012; timreview.ca/ article/603). In fact, Ballon, Pierson, and Delaere (2005; tinyurl.com/8hox58r) differentiate between living labs in real-life environments from test beds in controlled laboratory environments. A user is an object to be studied in a test bed, whereas in a living lab, the user acts as a subject, is an equal co-creator, and adopts more versatile roles (Ballon et al., 2005: tinyurl.com/8hox58r; Leminen and Westerlund, 2012; tinyurl.com/orlnfh5).

Almirall and Wareham (2011; tinyurl.com/lrz3dg2) argue that a living lab acts as an intermediary between various actors. Dutilleul, Birrer, and Mensink (2010; tinyurl.com/ k3v3yzo) propose that living labs form a central point for innovation in multi-organizational collaboration. Westerlund and Leminen (2011; timreview.ca/article/489) identify distinct actors in living labs: providers, users, utilizers, and enablers. These groups of actors form a core of roles that are adapted and changed based on selected operations and desired outcome (Nyström, Leminen, Westerlund, and Kortelainen, 2014: forthcoming in Industrial Marketing Management; tinyurl.com/ kn63gxw). A living lab supports collaboration and knowledge exchange between actors and acts as a platform for stimulating both the shared goal of the living lab and the goals of individual actors (Leminen and Westerlund, 2012; tinyurl.com/orlnfh5). According to Stewart (2007; tinyurl.com/6cx2pfb) and Leminen and colleagues (2011; tinyurl.com/n3tfz2a), living labs can be categorized by the driving actor in a network.

To sum up, prior research lacks a consistent definition for living labs and related constructs. The literature on living labs shares the view that living labs refer to reallife environments and the "living lab approach" is embedded in living labs. The literature provides differing views of living lab approaches; most authors identify various actors and stress the importance of users (Eriks- 


\section{Coordination and Participation in Living Lab Networks}

Seppo Leminen

son et al., 2005: tinyurl.com/8fv3jkp; Ballon et al., 2005: tinyurl.com/8hox58r; Westerlund and Leminen, 2011: timreview.ca/article/489). However, the diverse roles of stakeholders in living labs are under-researched (Nyström, Leminen, Westerlund, and Kortelainen, 2014: forthcoming in Industrial Marketing Management; tinyurl.com/kn63gxw). Some scholars view the approach as activities conducted at living labs (de Leon et al., 2006; tinyurl.com/lloveun) and emphasize the resources of actors in living labs (Leminen and Westerlund, 2012; tinyurl.com/orlnfh5). Thus, actors, activity, and resources can be seen as key elements of living lab networks. Such networks have been discussed as open innovation intermediaries (Almirall and Wareham, 2011; tinyurl.com/lrz3dg2), innovation networks (Leminen and Westerlund, 2012; tinyurl.com/orlnfh5), milieus (BergvallKåreborn et al., 2009; tinyurl.com $/ \mathrm{m} 6 \mathrm{kn} 9 \mathrm{mu}$ ), innovation environments (Mulder and Stappers, 2009; tinyurl.com/ 9f75ndh), networks of rural development (Schaffers and Kulkki, 2007; tinyurl.com/mplfq9e), and networks of living labs as the innovation system (Dutilleul et al., 2010; tinyurl.com/k3v3yzo). Table 1 summarizes the characteristics and definitions of living labs from different perspectives.

In accordance with Westerlund and Leminen (2011; timreview.ca/article/489), this study defines living labs as "physical regions or virtual realities, or interaction spaces, in which stakeholders form public-privatepeople partnerships (4Ps) of companies, public agencies, universities, users, and other stakeholders, all collaborating for creation, prototyping, validating, and testing of new technologies, services, products, and systems in real-life contexts."

\section{Top-down and Bottom-up Approaches}

Sabatier (1986; tinyurl.com/19o9az9) reviewed literature about bottom-up and top-down approaches in public policy making and concluded that the two approaches have different features and are applicable in different situations. To simplify these approaches, a top-down approach is merely led or coordinated to accomplish centralized and official targets, whereas a bottom-up approach operates at the grassroots level and focuses on local needs. Sabatier argues that the bottom-up and top-down approaches often ignore the benefits of their opposite approaches; for example a formal strategy is not described in a bottom-up approach and a topdown approach often ignores the local needs of the many different participants.
Oxford English Dictionary (oed.com) defines top-down as "something that proceeds from the top downwards; authoritarian, hierarchical". At least two hierarchy types may be found to describe top-down and bottom-up in literature. The first hierarchy type is an authority structure, such as Weber's (1947; tinyurl.com/kreh7js) bureaucracy, where individuals at higher levels of the hierarchy have authority over individuals at lower levels. The second hierarchy type is a parts-within-parts containment structure, such as that of Simon (1962; tinyurl.com/jvhfwd5), where higher-level constructs (e.g., companies) are composed of lower level constructs (e.g., people). However, this article takes a different view; because living labs are facilitated rather than managed, they have no authority over individuals (Westerlund and Leminen, 2011; timreview.ca/article/489) and important roles of users are widely accepted. Opposite to the two previously identified hierarchy types, this study defines hierarchy as an innovation-facilitation mechanism to facilitate progress towards a given target. Consequently, this article defines a top-down approach in living labs as an authoritarian, hierarchical innovation approach that is directed, controlled, and proceeds from top to bottom when creating, prototyping, validating, and testing new technologies, services, products, and systems in real-life contexts. The opposite approach, a bottom-up approach in living labs, refers to an innovation approach in which emergent, grassroots ideas and needs are collectively developed, created, prototyped, and validated for mutual and shared objectives, new services, products, systems, and technologies in real-life contexts.

The open innovation literature provides various classifications of open innovation and openness. For instance, Bogers and West (2012; tinyurl.com/ba3gg3x) contrast and classify the concepts of open innovation (Chesbrough, 2003; tinyurl.com/nxupq2q) and user innovation (von Hippel, 2007; tinyurl.com/ohwh2fp). The classification does not explicitly address the top-down and bottom-approaches but implicitly depicts them. Chesbrough (2003; tinyurl.com/nxupq2q) submits that open innovation is a way for management innovation from a company perspective. This approach may be called company-led or top-down. Conversely, von Hippel (2007; tinyurl.com/ohwh2fp) puts forward that users or user communities solve their needs with the help of open innovation. This approach is community-led or bottom-up.

This study views bottom-up and top-down as the opposite ends of the coordination approach in living labs. 


\section{Coordination and Participation in Living Lab Networks}

\section{Seppo Leminen}

Table 1. Different perspectives on living labs

\begin{tabular}{|c|c|c|}
\hline Characteristics & Definition & Examples \\
\hline $\begin{array}{l}\text { - Real-life environment } \\
\text { - Multi-stakeholder approach: users, public, } \\
\text { firms, and academia } \\
\text { - Multi-contextual } \\
\text { - User as innovator }\end{array}$ & $\begin{array}{l}\text { An R\&D methodology to create and validate in a } \\
\text { collaborative, multi-contextual, empirical real-world } \\
\text { environment, with users playing a central role as } \\
\text { innovators }\end{array}$ & $\begin{array}{l}\text { Eriksson, Niitamo, \& Kulkki (2005) } \\
\text { tinyurl.com/8fv3jkp }\end{array}$ \\
\hline $\begin{array}{l}\text { - Openness } \\
\text { - Public involvement } \\
\text { - Commercial maturity } \\
\text { - Vertical scope } \\
\text { - Scale } \\
\text { - Duration }\end{array}$ & $\begin{array}{l}\text { "An experimentation environment in which } \\
\text { technology is given shape in real-life contexts and in } \\
\text { which (end) users are considered 'co-producers"” p. } 5\end{array}$ & $\begin{array}{l}\text { Ballon et al. (2005) } \\
\text { tinyurl.com/8hox58r }\end{array}$ \\
\hline
\end{tabular}

- $R \& D$ methodology

- User-centred, real-life approach

- Collaborative multi-contextual environments

- Design, test, validate and develop

- Co-creation by real consumer and end users

- Living lab network

- Experimentation and validation environments

- User centric

- Catalyze rural and regional systems of innovations

- Cooperation between users, technology, and application

- Network of rural living labs

- Milieu (environment, arena)

- Approach (methodology, innovation approach)

"A user-centric innovation milieu built on every-day practice and research, with an approach that facilitates user influence in open and distributed innovation processes engaging all relevant partners in real-life contexts, aiming to create sustainable values" p.3

- Innovation environment

- Real-life setting

- User-driven

- Living lab network

\begin{abstract}
"An R\&D methodology where innovations, such as new services, products, or applications enhancements, are created and validated in collaborative, multicontextual, empirical, real-world environments within individual regions" p. 1
\end{abstract}

"As experimentation and validation environments characterized by early involvement of user communities, closely working together with developers and other stakeholders, and driving rapid cycles of ICT-based innovations" p.31
"Not a network of infrastructure and services" but also "a living network of real people with rich experiences." de Leon et al. (2006) tinyurl.com/lloveun
Schaffers \& Kulkki (2007)

tinyurl.com/mplfq9e
- Network of living labs as an innovation system

- Multi-stakeholder

- Contact, communication, and collaboration

- Open innovation intermediary

- Exploration and exploitation

- Innovation types and outcomes
A social configuration that is organized for innovation creation by contact, communication, and collaboration.
Bergvall-Kåreborn et al. (2009)

tinyurl.com/m6kn9mu

Mulder \& Stappers (2009)

tinyurl.com/9f75ndh

\begin{abstract}
"Open innovation intermediaries that seek to mediate between users, research, and public and private organizations, [and to] advance our concept of technology transfer by incorporating not only the user-based experimentation, but also by engaging firms and public organizations in a process of learning and the creation of pre-commercial demand" p. 100
\end{abstract}

Dutilleul et al. (2010)

tinyurl.com $/ \mathrm{k} 3 \mathrm{v} 3 \mathrm{yzo}$

Almirall \& Wareham (2011) tinyurl.com/lrz3dg2
- Multi-stakeholder approach; user, provider, enabler, and utilizer

- A form of open innovation

- Co-creation with users
As "experimentation environments; they are physical regions or virtual realities where stakeholders form public-private-people partnerships (4Ps) of firms, public agencies, universities, institutes, and users all collaborating for creation, prototyping, validating, and testing of new technologies, services, products and systems in real-life contexts" p. 20

- Multi-actor innovation network

- Role, resource, objective, motivation, and outcome
As a multi-actor innovation network that "employs heterogeneous roles and resources", "shares information to enable flexibility", "reveals undefined and latent needs", and where the "lack of strict objectives guides collaboration and outcomes".
Westerlund \& Leminen (2011)

timreview.ca/article/489
Leminen \& Westerlund (2012) tinyurl.com/orlnfh5 


\section{Coordination and Participation in Living Lab Networks}

Seppo Leminen

In the following sections, the study depicts how previous research on living labs distinguishes these two opposite ends and their combinations. For example, Pascau and van Lieshout (2009; tinyurl.com/cmrkjlw) found that living labs involve bottom-up activities rather than top-down control. Følstad (2008; tinyurl.com/ m9wa2dc) and Schuurman and colleagues (2011; tinyurl.com/lij3xsk) propose "bottom-up" as a construct consisting of nine characteristics for describing living labs. Furthermore, Budweg and colleagues (2011; tinyurl.com/8u3yhvv) argue that a top-down approach is linked to the structure and mechanism for managing technology adaptions in organizational settings within living labs, whereas a bottom-up approach is a tool for adaption opportunities as well as a strategy and a process for local stakeholders.

Leminen and colleagues (2011; tinyurl.com/n3tfz2a) propose that top-down and bottom-up are principles for innovation development in living labs networks. Moreover, Leminen, Westerlund, and Nyström (2012; timreview.ca/article/602) argue that a top-down approach is a principle for managing innovation development in an open innovation network, whereas a bottom-up approach is a principle for facilitating innovation development in networks. Lievens and colleagues (2011; tinyurl.com/mgcxfap) view living labs as a combination of bottom-up and top-down development; whereas a bottom-up approach is a source for needs and requirements, a top-down approach acts as need validation for ideas and concepts. Furthermore, Sauer (2012; tinyurl.com/om2e6gg) identifies the need for integration of bottom-up approach as a source of unanticipated ideas and top-down approach as a formal structure for living labs. Finally, Tang and colleagues (2012; tinyurl.com/kygmlmu) propose a duality model of a living lab that integrates both company-led innovation and a grassroots innovation model (i.e., top-down and bottom-up approaches). Table 2 summarizes previous research and identifies the characteristics of top-down and bottom-up approaches in living lab research.

To sum up, the current literature on living labs distinguishes two diverse streams on coordination in open innovation networks. The first stream assumes that the network is coordinated by the needs and wishes of a single party. It further assumes that innovation is driven by an individual actor in an open network and takes either a top-down or bottom-approach. The second stream assumes that innovation development in open innovation networks takes place in combination with both top-down and bottom-up approaches. This synthesis may be found in innovation networks with mul- tiple actors such as in living labs. This study applies the first literature stream on coordination; the second stream fails to address that an innovation network is driven by a single actor and that all actors may have goals of their own as well as shared goals (Leminen and Westerlund, 2012; tinyurl.com/orlnfh5).

\section{Methodology}

This study employed a qualitative research approach in analyzing 26 living labs in four countries: Finland, South Africa, Spain, and Sweden. These countries were chosen because of their diversity and number of living labs and their leading-edge positions of establishing living lab networks (European Network of Living Labs, 2012; enoll.org). There is a good potential for transferability of findings because this sample can be considered representative of countries having existing living labs. The cases were selected according to following criteria: i) each case must apply a living labs approach based on open innovation initiatives; ii) each case must include the development of a new product/service, a business concept, or social innovation with multiple actors; and iii) each case must involve users, user groups, or a user community in their everyday life or a simulation.

The data was collected between 2008 and 2011, and included interviews with 103 participants from living labs. The purpose of the interviews was to increase the understanding of innovation mechanisms in living labs. The interviews were carried out as face-to-face discussions, which lasted typically between 60 to 90 minutes. Primary data informants were CEOs, CTOs, sales directors, project managers, researchers, project coordinators, and users. Core actors were selected in every living lab, because not all stakeholders could be interviewed in each living lab. The interviews covered themes such as background information, organizing the living lab, actualizing the living lab, and as well as results and outcomes of innovation in living labs.

Websites, bulletins, magazines, and case reports comprised the secondary data source for the study. In the first phase, the empirical data was systematized according to living lab, date of interview, and type of informant. This study analyzed and coded actors and driving actors from transcribed interview data without prior assumptions about actors (i.e., using open coding). Then, this study applied focused coding: the explored categorization was compared to the conceptualization of driven actors by Leminen, Westerlund, and Nyström (2012; timreview.ca/article/602). 


\section{Coordination and Participation in Living Lab Networks}

\section{Seppo Leminen}

Table 2. Top-down and bottom-up approaches in prior literature on living labs

\begin{tabular}{|c|c|c|}
\hline Construct & Definition of construct & Sources \\
\hline \multirow[t]{5}{*}{ Top-down } & $\begin{array}{l}\text { Top-down as a structure and mechanism for managing } \\
\text { technology adaptations in an organizational setting }\end{array}$ & $\begin{array}{l}\text { Budweg et al. (2011) } \\
\text { tinyurl.com/8u3yhvv }\end{array}$ \\
\hline & Top-down as a need validation in experimental situations & $\begin{array}{l}\text { Lievens et al. ( } 2011 \text { ) } \\
\text { tinyurl.com/le8xfuc }\end{array}$ \\
\hline & Top-down as a principle for innovation development & $\begin{array}{l}\text { Leminen et al. (2011) } \\
\text { tinyurl.com/n3tfz2a }\end{array}$ \\
\hline & $\begin{array}{l}\text { Top-down as a principle for managing innovation } \\
\text { development in networks }\end{array}$ & $\begin{array}{l}\text { Leminen et al. (2012) } \\
\text { timreview.ca/article/ } 602\end{array}$ \\
\hline & Top-down as a company-led innovation model & $\begin{array}{l}\text { Tang et al. (2012) } \\
\text { tinyurl.com/kygmlmu }\end{array}$ \\
\hline \multirow[t]{8}{*}{ Bottom-up } & $\begin{array}{l}\text { Bottom-up as a construct of nine characteristics for } \\
\text { describing living labs }\end{array}$ & $\begin{array}{l}\text { Følstad }(2008) \\
\text { tinyurl.com/m9wa2dc }\end{array}$ \\
\hline & & $\begin{array}{l}\text { Schuurman et al. (2011) } \\
\text { tinyurl.com/lj39xsk }\end{array}$ \\
\hline & Bottom-up as user's role in innovation process & $\begin{array}{l}\text { Pascau \& van Lieshout (2009) } \\
\text { tinyurl.com/cmrkjlw }\end{array}$ \\
\hline & $\begin{array}{l}\text { Bottom-up as a tool for adaption opportunities for local } \\
\text { stakeholders as well as strategy and process }\end{array}$ & $\begin{array}{l}\text { Budweg et al. (2011) } \\
\text { tinyurl.com/8u3yhwv }\end{array}$ \\
\hline & Bottom-up as a source of needs and requirements & $\begin{array}{l}\text { Lievens et al. (2011) } \\
\text { tinyurl.com/le8xfuc }\end{array}$ \\
\hline & Bottom-up as a principle for innovation development & $\begin{array}{l}\text { Leminen et al. (2011) } \\
\text { tinyurl.com/n3tfz2a }\end{array}$ \\
\hline & $\begin{array}{l}\text { Bottom-up as a principle for facilitating innovation } \\
\text { development in networks }\end{array}$ & $\begin{array}{l}\text { Leminen et al. (2012) } \\
\text { timreview.ca/article/602 }\end{array}$ \\
\hline & Bottom-up as grassroots innovation for communities & $\begin{array}{l}\text { Tang et al. (2012) } \\
\text { tinyurl.com/kygmlmu }\end{array}$ \\
\hline
\end{tabular}




\section{Coordination and Participation in Living Lab Networks}

\section{Seppo Leminen}

In the third phase, this study investigated thoroughly each living lab case to describe the coordination approach and compare it to Sabatier's (1986; tinyurl.com/ 1909az9) typology. In the fourth phase, this study detected previously unknown participation approaches ("inhalation dominated" versus "exhalation dominated") to distinguish innovation in living labs based on case analysis. Finally, this study synthesized the results and concluded by describing the coordination approach and participation approach. Table 3 synthesizes the data analysis process and its phases.

\section{Findings}

Based on the analysis, this study developed the framework shown in Figure 1. The framework forms a matrix of innovation mechanisms in living lab networks and thereby illustrates a coordination approach ("topdown" versus "bottom-up") and a participation approach ("exhalation-dominated" versus "inhalationdominated") with four previously identified types of living lab network options (Leminen et al., 2012; timreview.ca/article/602). The first dimension is grounded on the coordination of innovation activities or initiatives in living lab networks. Innovation activities take place either through a top-down approach or a bottom-up approach (Sabatier, 1986; tinyurl.com/19o9az9).

The second dimension is the previously unknown participation approach to innovation, which was detected based on the case analysis. This study distinguishes the participation approach and its two extremes: exhala-

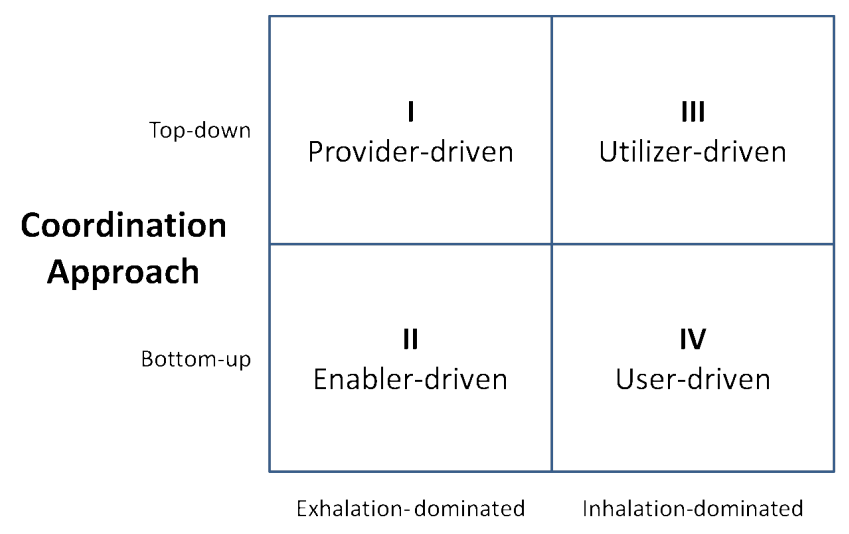

Participation Approach

Figure 1. A matrix of innovation mechanisms in living lab networks

tion dominated and inhalation dominated. The study proposes that the inhalation-dominated innovation approach, or "out-in approach", is initiated and targeted at fulfilling the needs of a driving party by engaging other stakeholders in innovation activities. This approach encourages parties to bring their knowledge, expertise, and resources into the open innovation network. The exhalation-dominated innovation approach, or "in-out approach", does not primarily fulfill a need of the driving actor, but rather the requirements and wishes of other stakeholders. This approach engages stakeholders for collective action in the open innovation network. This study stresses that the "out-in approach" and the "in-out

Table 3. Data analysis process

\begin{tabular}{|c|c|c|}
\hline Data Analysis Phases & Task & Outcome \\
\hline 1. Open coding & $\begin{array}{l}\text { - Organize living lab cases } \\
\text { - Identify actors in each case }\end{array}$ & Overview of living lab cases \\
\hline 2. Focused coding & - Identify the driving actor in each living lab & $\begin{array}{l}\text { Determination of the driving actor } \\
\text { (Leminen et al., 2012) in each living } \\
\text { lab case }\end{array}$ \\
\hline 3. Focused coding & $\begin{array}{l}\text { - Identify and analyze coordination approach } \\
\text { - Compare data to theory }\end{array}$ & $\begin{array}{l}\text { Classification of coordination } \\
\text { approaches based on Sabatier (1986) }\end{array}$ \\
\hline $\begin{array}{l}\text { 4. Identifying innovation in living } \\
\text { lab networks }\end{array}$ & $\begin{array}{l}\text { - Identify for whom innovation activities are } \\
\text { conducted }\end{array}$ & $\begin{array}{l}\text { Detection of previously unknown } \\
\text { participation approach to innovation }\end{array}$ \\
\hline 5. Theorizing the codes & - Synthesize phases 1 to 4 & $\begin{array}{l}\text { Findings and results on innovation } \\
\text { development in living labs }\end{array}$ \\
\hline
\end{tabular}




\section{Coordination and Participation in Living Lab Networks}

Seppo Leminen

approach" are dissimilar to earlier open innovation concepts of "in-side out" and "out-side in", given that the inside-out concept refers to the commercialization of ideas and technology and the outside-in concept refers to the acquisition and sourcing of external knowledge for a company (Enkel et al., 2009; tinyurl.com/mspeap8).

Figure 1 synthesizes the results from the analysis in living labs. It illustrates four different types of living lab networks and shows the dependencies of coordination and participation approaches in these networks. The framework is considered a key outcome of this study because inhalation- and exhalation-dominated innovation have not been discussed in prior innovation literature.

All four types of living lab networks typically include similar actor roles: user, utilizer, provider, and enabler. However, the networks differ by: i) the driving party (i.e., a living lab stakeholder who leads the innovation activities); ii) coordination of innovation; and iii) participation in those networks. Provider-driven and utilizerdriven living labs are top-down coordinated, which mean that innovation activities are typically directed and controlled from the top downward. In contrast, user-driven and enabler-driven living labs are characterized by bottom-up coordination of the development, creation, and validation of ideas at the grassroots level.

Both provider-driven and enabler-driven living labs were associated with exhalation dominance as their participation approach, which is the second outcome of this study. A provider-driven living lab (i.e., model 1, as depicted in the top-left corner of Figure 1) has multiple tasks. The living lab is used, for example, to offer services to the utilizers, to offer solutions to the needs of other stakeholders, or to educate students as a part of research project in living labs. The following quotes from the interviews exemplify the exhalation-dominated approach.

As the CEO of a provider-driven living lab in Finland explained:

"We have been talking with a food company. They were very interested in doing the ideation process with us on... let's say, what the future of eating is. How people are going to eat in the future, what you are going to cook, and how you are going to consume it are, of course, heavily influenced by the means you have to make it... You can imagine that, by doing such an analysis with them, you will get ideas on whom we should have around the table to have the right ideas about the future of eating."
On the other hand, an enabler-driven living lab (i.e., model II, as depicted in the bottom-left corner of Figure 1) collects development needs from the region, its associations, its occupants, and its user communities; in other words, it follows a bottom-up approach. It also offers to provide outcomes for these needs, and is therefore exhalation dominated. Typically, an enabler-driven living lab creates activities to serve and improve living conditions of citizens and communities in a geographically restricted area. For instance, the Director of an enabler-driven living lab in Spain described:

"We want to develop a project to help to people with mental and physical handicaps or disease. The reason is that we want to let these people live wherever they want, even in rural areas, because for some things they have to go to big cities to receive [services, facilities]... and because of this project, the people receive the services or the facilities they need without moving, without the obligation to move to... see other, if in other places there are facilities to reach these objectives."

The analysis of this study links utilizer-driven and userdriven living labs to the inhalation-dominated approach to participation, which is the third key result of this study. Both provider-driven and enabler-driven were associated with exhalation dominance in the participation approach.

In a utilizer-driven living lab, innovation activities are typically directed, controlled, and initiated from the top downward, and follow an exhalation-dominated approach, and the innovation activities are conducted to meet the needs of the utilizers. In other words, a utilizer typically uses a living lab as a mechanism and resource spring to develop and create new ideas, concepts, or prototypes or to validate and test concepts, products, and services. Consider the following quote from a Project Manager from a utilizer-driven living lab in Finland:

"Living labs, from my point of view, are controlled environments in which real users can evaluate and test early prototypes or work-in-progress products and services. [In those controlled environments] we can observe them, and we can collect feedback from them, and identify problems and development needs."

In contrast, a user-driven living lab is based on an assumption that development needs come from individual users or a user community (i.e., bottom-up), and results or findings of innovation activities are delivered for the need of the users or user community (i.e., inhalation-dominated). A user-driven living lab (i.e., model IV, as depicted in the bottom-right corner of Figure 1) focuses on improving the everyday life conditions or 


\section{Coordination and Participation in Living Lab Networks}

Seppo Leminen

activities of its users. For example, as described by the manager of a user-driven living lab in Sweden:

"We pay some extra attention to them. And when we work with them, they have ideas that they want, for example, to produce music. They want to do hip hop in new ways. They want to have a music club where something exciting is happening. Or they want to share their music. So, what we try to do is connect technology and ideas that could help them spread word about the music. Help them make exciting things happen in their club. So, they are doing this because we are helping them improve their everyday activities. So, it is important that it makes sense to them. It must make sense to them; it must be meaningful to them, to participate in experiments."

\section{Conclusion}

This research focused on understanding the coordination and participation approaches in living lab networks. The study highlighted three main results. First, the study introduced a framework in the form of an innovation-mechanism matrix to identify and analyze distinct living lab networks. The framework was grounded on two dimensions: coordination approach ("topdown" versus "bottom-up") and participation approach ("inhalation-dominated" versus "exhalationdominated"). Inhalation and exhalation dominance have not been discussed in prior innovation literature. These two approaches are important for living lab research: coordination and participation approaches enable researchers to distinguish different types of living lab networks, which is still an under-researched topic in the domain of living labs. This study also propose that coordination and participation approaches may have broader applicability for other forms of open innovation, where the current classification literature (e.g., Bogers and West, 2010: tinyurl.com/ba3gg3x; Dahlander and Gann, 2010: tinyurl.com/chacrs9; Huizingh, 2011: tinyurl.com/kfqyd4l) does not cover these approaches. Second, the provider-driven and enabler-driven living labs are identified exhibit exhalation dominance in their participation approach. Third, the utilizer-driven and user-driven living labs are associated with inhalation-dominance in their participation approach.
This study addressed four previously identified types of living labs (cf. Leminen et al., 2012; timreview.ca/article/ 602) and explained their coordination and participation approaches using empirical data from a number of living labs as evidence. For managers, the study provides a framework - a practical tool - for depicting different living lab approaches. The results enable managers to pursue innovation development with open innovation communities by focusing on the variety of coordination and participation approaches in diverse open innovation networks.

There are always limitations in research. Extensive data was collected from a number of actors and living labs, but the interviews only covered a limited number of labs over a short time span. Prior research on living labs proposes the need for iterative initiatives (e.g., Schuurman et al., 2011; tinyurl.com/lij39xsk). Therefore, it would helpful expand the duration of the study and include multiple projects and initiatives within each living lab. Acknowledging these limitations, this study calls for more research on the longitudinal perspective of living labs and other open innovation networks. More specifically, new research questions may be articulated: "Can a different actor drive innovation in a subsequent case at the same living lab?"If so, how does a change of the driving actor affect the coordination and participation approaches to innovation?

\section{Recommended Reading}

- "Incremental and Radical Service Innovation in Living Labs" (Leminen and Westerlund, 2013; tinyurl.com/n32nlsx)

\section{Acknowledgements}

The author gratefully appreciates two anonymous blind reviewers and the editor of chief for their valuable comments, suggestions, and guidelines to improve this article. Special thanks are also extended to all of the interviewees, who kindly shared their knowledge and experience as stakeholders in living labs. 


\section{Coordination and Participation in Living Lab Networks}

Seppo Leminen

\section{About the Author}

Seppo Leminen holds positions as Principal Lecturer at the Laurea University of Applied Sciences and Adjunct Professor in the School of Business at Aalto University in Finland. He holds a doctoral degree in Marketing from the Hanken School of Economics and a licentiate degree in Information Technology from the Helsinki University of Technology (now the School of Electrical Engineering at Aalto University). His doctoral research focused on perceived differences and gaps in buyer-seller relationships in the telecommunication industry. His research and consulting interests include living labs, open innovation, value co-creation and capture with users, neuromarketing, relationships, services, and business models in marketing as well as management models in high-tech and service-intensive industries. Results from his research have been reported in numerous scholarly journals, including Management Decision, the International Journal of Product Development, and the Technology Innovation Management Review, among many others.

Citation: Leminen, S. 2013. Coordination and

Participation in Living Lab Networks. Technology

Innovation Management Review. November 2013: 5-14.

Keywords: open innovation, living lab, coordination, participation, innovation approach, top-down, bottomup, exhalation-dominated, inhalation-dominated, userdriven, provider-driver, enabler-driven, utilizer-driven, open innovation network, living lab network 